Kaplan-Meier estimates of treatment persistence for ustekinumab and TNFi in the overall PsABio Italian cohort

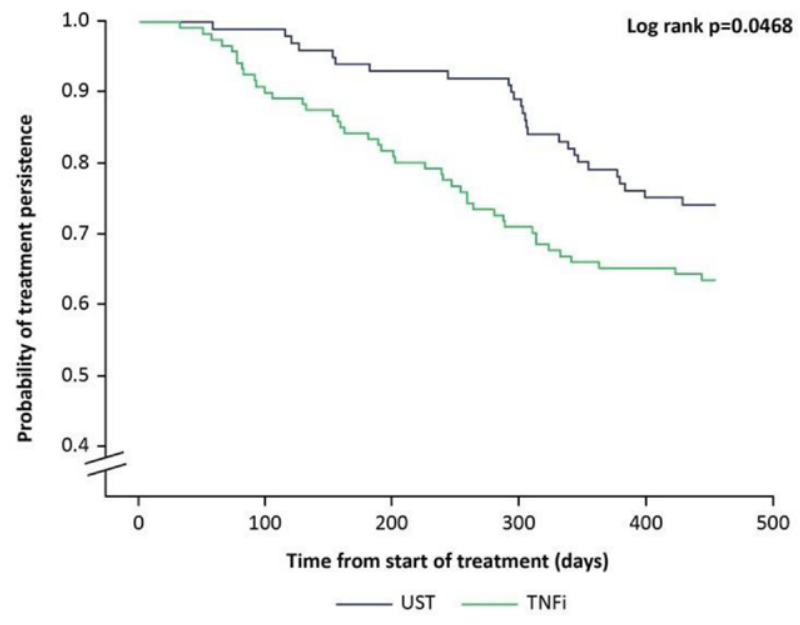

TNFi, tumour necrosis factor inhibitor

was 26.3 (15.4) for UST and 23.5 (12.3) for TNFi; at 1-year follow-up, 43.5\% of UST- and $43.6 \%$ of TNFi-treated patients reached cDAPSA LDA/remission. MDA was reached in $24.2 \%$ of UST- and $28.0 \%$ of TNFi-treated patients, and VLDA in $12.5 \%$ of UST- and $10.2 \%$ of TNFi-treated patients. After PS adjustment (stoppers/switchers as non-responders), odds ratios $(95 \% \mathrm{Cl})$ at 1 year did not differ significantly between UST and TNFi groups for reaching cDAPSA LDA/remission $(1.08[0.54 ; 2.15]), \operatorname{MDA}(0.96[0.45 ; 2.05])$ or VLDA $(0.98[0.35 ; 2.76])$. In total, 23 $(20.4 \%)$ patients reported $\geq 1$ treatment emergent adverse event with UST and $30(22.2 \%)$ with TNFi; 6 (5.3\%) and 10 (7.4\%) patients, respectively, discontinued treatment because of an adverse event.

Conclusion: In the Italian PsABio cohort, UST had better overall persistence compared with TNFi, as well as in specific subgroups: females, patients on monotherapy without methotrexate, with $\mathrm{BMI}<25$ or $>30 \mathrm{~kg} / \mathrm{m}^{2}$, and patients receiving UST as 2nd-line treatment. At 1 year, both treatments showed similar effectiveness, as measured by cDAPSA responses and MDA/VLDA achievement.

Acknowledgements: This study was funded by Janssen. Contributing author: Prof. Piercarlo Sarzi-Puttini, ASST Fatebenefratelli-Sacco, University of Milan, Italy

Disclosure of Interests: Elisa Gremese: None declared, Francesco Ciccia Speakers bureau: AbbVie, Abiogen, Bristol-Myers Squibb, Celgene, Janssen, Lilly, Novartis, Pfizer, Roche, Consultant of: Celgene, Janssen, Lilly, Novartis, Pfizer, Roche, Grant/research support from: Celgene, Janssen, Novartis, Pfizer, Roche, Carlo Selmi Speakers bureau: AbbVie, Alfa-Wassermann, Amgen, Biogen, Celgene, Eli Lilly, Gilead, Janssen, MSD, Novartis, Pfizer, Sanofi-Genzyme, Consultant of: AbbVie, Alfa-Wassermann, Amgen, Biogen, Celgene, Eli Lilly, Gilead, Janssen, MSD, Novartis, Pfizer, Sanofi-Genzyme, Grant/research support from: AbbVie, Amgen, Janssen, Pfizer, Giovanna CUOMO: None declared, Rosario Foti Speakers bureau: AbbVie, Bristol-Myers Squibb, Celgene, Lilly, MSD, Janssen, Roche, Sanofi, Consultant of: AbbVie, Bristol-Myers Squibb, Celgene, Lilly, MSD, Janssen, Roche, Sanofi, Marco Matucci Cerinic Speakers bureau: Actelion, Biogen, Janssen, Lilly, Consultant of: Chemomab, Grant/ research support from: MSD, Fabrizio Conti Consultant of: AbbVie, Bristol-Myers Squibb, Galapagos, Lilly, Pfizer, Enrico Fusaro Speakers bureau: AbbVie, Amgen, Lilly, Grant/research support from: AbbVie, Pfizer, Giuliana Guggino Speakers bureau: AbbVie, Celgene, Novartis, Pfizer, Sandoz, Grant/research support from: Celgene, Pfizer, Florenzo lannone Speakers bureau: AbbVie, Bristol-Myers Squibb, Celgene, Lilly, MSD, Novartis, Pfizer, Sanofi, UCB, Consultant of: AbbVie, Bristol-Myers Squibb, Celgene, Lilly, MSD, Novartis, Pfizer, Sanofi, UCB, Andrea Delle Sedie: None declared, Roberto Perricone: None declared, Luca Idolazzi Speakers bureau: AbbVie, Eli Lilly, Janssen, MSD, Novartis, Sandoz, Paolo Moscato: None declared, Elke Theander Employee of: Janssen, Wim Noel Employee of: Janssen, Paul Bergmans Shareholder of: Johnson \& Johnson, Employee of: Janssen, Silvia Marelli Employee of: Janssen, Laure Gossec Consultant of: AbbVie, Amgen, Bristol-Myers Squibb, Biogen, Celgene, Galapagos, Gilead, Janssen, Lilly, Novartis, Pfizer, Samsung Bioepis, Sanofi-Aventis, UCB, Grant/research support from: Amgen, Galapagos, Janssen, Lilly, Pfizer, Sandoz, Sanofi, Josef S. Smolen Speakers bureau: AbbVie, Amgen, AstraZeneca, Astro, Bristol-Myers Squibb, Celgene, Celltrion, Chugai, Gilead, ILTOO, Janssen, Lilly, MSD, Novartis- Sandoz, Pfizer, Roche, Samsung, Sanofi, UCB, Grant/research support from: AbbVie, AstraZeneca, Lilly, Novartis, Roche.

DOI: 10.1136/annrheumdis-2021-eular.81

\section{POS1022 \\ BIMEKIZUMAB SAFETY AND EFFICACY IN PATIENTS WITH PSORIATIC ARTHRITIS: 3-YEAR RESULTS FROM A PHASE 2в OPEN-LABEL EXTENSION STUDY}

L. C. Coates $^{1}$, R. B. Warren ${ }^{2}$, C. T. Ritchlin ${ }^{3}$, L. Gossec ${ }^{4}$, J. F. Merola ${ }^{5}$, D. Assudani ${ }^{6}$, J. Coarse ${ }^{7}, \mathrm{~J}$. Eells ${ }^{6}$, B. Ink ${ }^{6}$, I. Mcinnes ${ }^{8} .{ }^{1}$ University of Oxford, Nuffield Department of Orthopaedics, Rheumatology and Musculoskeletal Diseases, Oxford, United Kingdom; ${ }^{2}$ The University of Manchester, Dermatology Centre, Manchester NIHR Biomedical Research Centre, Manchester, United Kingdom; ${ }^{3}$ University of Rochester, Medical Center, Rochester, United States of America; ${ }^{4}$ Sorbonne Université and Pitié-Salpêtrière Hospital, Department of Rheumatology, Paris, France; ${ }^{5}$ Brigham and Women's Hospital, Harvard Medical School, Boston, United States of America; ${ }^{6}$ UCB Pharma, N/A, Slough, United Kingdom; ${ }^{7}$ UCB Pharma, N/A, Raleigh, United States of America;

${ }^{8}$ University of Glasgow, School of Medicine, Glasgow, United Kingdom

Background: Bimekizumab (BKZ), a monoclonal antibody inhibitor of interleukin (IL)-17A and IL-17F, demonstrated clinical improvements in joint and skin outcomes up to 108 weeks (wks) in patients (pts) with active psoriatic arthritis (PsA). ${ }^{1,2}$

Objectives: To report up to 3-year safety and efficacy of BKZ in pts with active PsA from a 48-week phase $2 b$ dose-ranging study (BE ACTIVE; NCT02969525) and its open-label extension (OLE; NCT03347110).

Methods: BE ACTIVE and OLE study design has been described previously. ${ }^{1}$ All OLE pts received BKZ $160 \mathrm{mg}$ Q4W, irrespective of prior dosing regimen. Treatment-emergent adverse events (TEAEs) are reported for the safety set (SS; pts who received $\geq 1$ dose $B K Z$ in the dose-ranging study). Data are presented from dose-ranging study baseline (BL) to Wk 152. Efficacy outcomes are reported for the full analysis set (FAS): ACR50, minimal or very low disease activity (MDA VLDA), Psoriasis Area and Severity Index (PASI) 90/100, body surface area affected by psoriasis (BSA) $0 \%$ and dactylitis/enthesitis resolution.

Results: Over 152 wks, the exposure-adjusted incidence rate (EAIR) per 100 patient-years (PY) was 126.4 for all TEAEs, 4.1 for serious TEAEs, 0.7 for serious infections and 4.6 for Candida infections (Table 1). One event was adjudicated by an independent committee as inflammatory bowel disease (microscopic colitis). All Candida infections were localised, mild/moderate, and resolved with appropriate anti-fungal therapy. Overall, the proportions of patients with ACR50 response were sustained through Wk 152 (52.9\%, non-responder imputation [NRI]; Figure 1). Response rates were also sustained through Wk 152 for MDA (51.5\%), VLDA (30.1\%), PASI90 (64.2\%), PASI100 (57.7\%) and resolution of dactylitis $(71.2 \%)$ and enthesitis $(62.6 \%)$ (NRI; Table 1$)$

Table 1. Safety and efficacy outcomes up to 3 years

\begin{tabular}{|c|c|c|c|c|c|c|}
\hline $\begin{array}{l}\text { Safety (SS) } \\
\text { n (\%) [EAIR/100 PY] }\end{array}$ & \multicolumn{2}{|c|}{$\begin{array}{c}\text { BKZ } \\
160 \mathrm{mg}[\mathrm{a}] \\
(\mathrm{n}=126)\end{array}$} & \multicolumn{2}{|c|}{$\begin{array}{c}\text { BKZ } \\
320 \mathrm{mg}[\mathrm{b}] \\
(\mathrm{n}=78)\end{array}$} & \multicolumn{2}{|c|}{$\begin{array}{c}\text { Total } \\
(\mathrm{N}=206)\end{array}$} \\
\hline Any TEAE & \multicolumn{2}{|c|}{$114(90.5)[136.1]$} & \multicolumn{2}{|c|}{70 (89.7) [113.3] } & \multicolumn{2}{|c|}{184 (89.3) [126.4] } \\
\hline $\begin{array}{l}\text { Serious TEAEs } \\
\text { Key TEAEs of special } \\
\text { monitoring }\end{array}$ & \multicolumn{2}{|c|}{$17(13.5)[5.2]$} & \multicolumn{2}{|c|}{$5(6.4)[2.3]$} & \multicolumn{2}{|c|}{$22(10.7)[4.1]$} \\
\hline Serious infections & \multicolumn{2}{|c|}{$3(2.4)[0.9]$} & \multicolumn{2}{|c|}{$1(1.3)[0.5]$} & \multicolumn{2}{|c|}{$4(1.9)[0.7]$} \\
\hline Candida infections & \multicolumn{2}{|c|}{15 (11.9) [4.7] } & \multicolumn{2}{|c|}{9 (11.5) [4.4] } & \multicolumn{2}{|c|}{$24(11.7)[4.6]$} \\
\hline $\begin{array}{l}\text { Inflammatory bowel } \\
\text { disease [c] }\end{array}$ & \multicolumn{2}{|c|}{$1(0.8)[0.3]$} & \multicolumn{2}{|c|}{0} & \multicolumn{2}{|c|}{$1(0.5)[0.2]$} \\
\hline Malignancies [d] & \multicolumn{2}{|c|}{$1(0.8)[0.3]$} & \multirow{2}{*}{\multicolumn{2}{|c|}{$\begin{array}{c}0 \\
3(3.8)[1.4]\end{array}$}} & \multicolumn{2}{|c|}{$1(0.5)[0.2]$} \\
\hline $\begin{array}{l}\text { Injection site } \\
\text { reactions }\end{array}$ & \multicolumn{2}{|c|}{0} & & & \multicolumn{2}{|c|}{$3(1.5)[0.5]$} \\
\hline Suicidal ideation & \multirow{2}{*}{\multicolumn{2}{|c|}{$\begin{array}{c}1(0.8)[0.3] \\
13(10.3)[4.1]\end{array}$}} & \multicolumn{2}{|c|}{0} & \multicolumn{2}{|c|}{$1(0.5)[0.2]$} \\
\hline $\begin{array}{l}\text { Liver function } \\
\text { analyses }\end{array}$ & & & $11(14.1)$ & ) $[5.3]$ & $24(11.7)[$ & [4.6] \\
\hline $\begin{array}{c}\text { Study discontinuation } \\
\text { due to TEAEs }\end{array}$ & \multicolumn{2}{|c|}{$12(9.5)$ [3.5] } & \multicolumn{2}{|c|}{$4(5.1)[1.8]$} & \multicolumn{2}{|c|}{$16(7.8)[2.8]$} \\
\hline Efficacy (FAS) & \multirow{2}{*}{\multicolumn{2}{|c|}{$\begin{array}{c}\text { BKZ } \\
160 \mathrm{mg}[\mathrm{a}] \\
(\mathrm{n}=124)\end{array}$}} & \multirow{2}{*}{\multicolumn{2}{|c|}{$\begin{array}{c}\text { BKZ } \\
320 \mathrm{mg}[\mathrm{b}] \\
(\mathrm{n}=82)\end{array}$}} & \multirow{2}{*}{\multicolumn{2}{|c|}{$\begin{array}{c}\text { Total } \\
(\mathrm{N}=206)\end{array}$}} \\
\hline \multirow[t]{2}{*}{ n (\%) } & & & & & & \\
\hline & OC & NRI, \% & OC & NRI, \% & oc & NRI, \% \\
\hline MDA, Wk 152 & $64 / 95(67.4)$ & 51.6 & $42 / 62(67.7)$ & 51.2 & $106 / 157(67.5)$ & 51.5 \\
\hline VLDA, Wk 152 & $41 / 95(43.2)$ & 33.1 & $21 / 62(33.9)$ & 25.6 & $62 / 157(39.5)$ & 30.1 \\
\hline PASI90 [e] Wk 152 & $51 / 61(83.6)$ & 64.6 & $37 / 46(80.4)$ & 63.8 & 88/107 (82.2) & 64.2 \\
\hline PASI100 [e] Wk 152 & $47 / 61(77.0)$ & 59.5 & $32 / 46(69.6)$ & 55.2 & 79/107 (73.8) & 57.7 \\
\hline BSA 0\% [e] Wk 48 & $48 / 72(66.7)$ & 60.8 & $38 / 55(69.1)$ & 65.5 & $86 / 127(67.7)$ & 62.8 \\
\hline Wk 152 & $46 / 61(75.4)$ & 58.2 & $31 / 45(68.9)$ & 53.4 & 77/106 (72.6) & 56.2 \\
\hline $\begin{array}{r}\text { Dactylitis [f]/Enthesitis } \\
\text { [g] resolution, Wk } 48\end{array}$ & $\begin{array}{l}5 \\
3\end{array}$ & $70.6 / 56.9$ & - & $84.0 / 57.1$ & - & $76.3 / 57.0$ \\
\hline Wk 152 & - & $67.6 / 63.1$ & - & $76.0 / 61.9$ & - & $71.2 / 62.6$ \\
\hline
\end{tabular}

No anaphylactic reactions or major adverse cardiac events were reported. [a] Includes pts within the indicated analysis set originally assigned to all arms who were subsequently re-randomized to $160 \mathrm{mg}$, or [b] $320 \mathrm{mg}$, after double-blind period; [c] Microscopic colitis; [d] Malignan melanoma in situ; [e] Pts with $B L B S A \geq 3 \%, N R I: n=79,58,137$ respectively; [f] Pts with BL LDI $>0, N R I: n=34,25,59$ respectively; [g] Pts with BL MASES $>0, N R I: n=65,42,107$ respectively LDI: Leeds Dactylitis Index; MASES: Maastricht AS Enthesitis Score; OC: observed case. 
Conclusion: The safety profile of BKZ in pts with PsA reflects previous observations ${ }^{1,2}$ for up to 3 years. High threshold disease control was achieved by $>50 \%$ of BKZ-treated pts up to 3 years, reflected in long-term improvements in joint and skin outcomes.

REFERENCES:

[1] Ritchlin CT. Lancet 2020;395:427-40;

[2] Mclnnes I. Ann Rheum Dis 2020;79:1153-4.

Figure. ACR50 responders up to 3 years

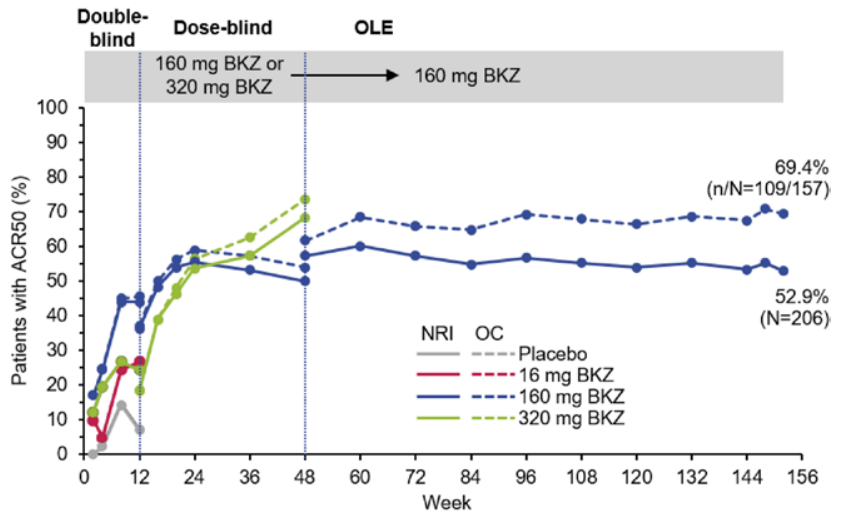

NRI and OC data shown for all timepoints from BL to Wk 152; pts randomised to placebo and $16 \mathrm{mg}$ shown through double-blind period; pts re-randomised at start of dose-blind period to either $160 \mathrm{mg}$ or $320 \mathrm{mg} \mathrm{BKZ;} \mathrm{190/206}(92.2 \%)$ patients randomised at BE ACTIVE study baseline completed Week 48. At Week 48, 181/206 (FAS; 87.9\%) patients entered the OLE; 157 patients had an efficacy assessment at Week 152; all OLE pts received $160 \mathrm{mg}$ BKZ regardless of prior dosing regimen

Acknowledgements: This study was funded by UCB Pharma. Editorial services were provided by Costello Medical.

Disclosure of Interests: Laura C Coates Speakers bureau: AbbVie, Amgen, Biogen, Celgene, Gilead, GSK, Janssen, Lilly, Medac, Novartis, Pfizer, UCB Pharma, Consultant of: AbbVie, Amgen, Biogen, Boehringer Ingelheim, Celgene, Domain, Gilead, Janssen, Lilly, Grant/research support from: AbbVie, Amgen, Celgene, Gilead, Janssen, Lilly, Novartis, Pfizer, UCB Pharma, Richard B. Warren Consultant of: AbbVie, Almirall, Amgen, Arena, Avillion, BMS, Boehringer Ingelheim, Celgene, Eli Lilly, Janssen, LEO Pharma, Novartis, Pfizer, Sanofi, UCB Pharma, Grant/research support from: AbbVie, Almirall, Amgen, Janssen, LEO Pharma, Novartis, UCB Pharma, Christopher T. Ritchlin Consultant of: Amgen, AbbVie, Lilly, Pfizer, Novartis, Gilead, Janssen, UCB Pharma, Grant/research support from: AbbVie, Amgen, UCB Pharma, Laure Gossec Speakers bureau: AbbVie, Amgen, Biogen, BMS, Celgene, Janssen, Lilly, Novartis, Pfizer, Samsung, Sanofi, UCB Pharma, Consultant of: AbbVie, Amgen, Biogen, BMS, Celgene, Janssen, Lilly, Novartis, Pfizer, Samsung, Sanofi, UCB Pharma, Grant/research support from: Eli Lilly, Pfizer, Sandoz, Joseph F. Merola Consultant of: AbbVie, Amgen, Bayer, Biogen, BMS, Celgene, Eli Lilly, Janssen, Novartis, Sanofi-Regeneron, Pfizer, UCB Pharma, Grant/research support from: AbbVie, Amgen, Bayer, Biogen, BMS, Celgene, Eli Lilly, Janssen, Novartis, Sanofi-Regeneron, Pfizer, UCB Pharma, Principal investigator for Dermavant, LEO Pharma, UCB Pharma, Deepak Assudani Employee of: UCB Pharma, Jason Coarse Employee of: UCB Pharma, Jason Eells Shareholder of: UCB Pharma, Employee of: UCB Pharma, Barbara Ink Shareholder of: GSK, UCB Pharma, Employee of: UCB Pharma, Iain McInnes Consultant of: AbbVie, BMS, Boehringer Ingelheim, Celgene, Lilly, Janssen, Novartis, UCB Pharma, Grant/research support from: BMS Boehringer Ingelheim, Celgene, Janssen, UCB Pharma. DOI: 10.1136/annrheumdis-2021-eular.124

\section{POS1023 HOW DOES GENDER AFFECT SECUKINUMAB TREATMENT OUTCOMES AND RETENTION RATES IN PATIENTS WITH PSORIATIC ARTHRITIS? - REAL WORLD DATA FROM THE GERMAN AQUILA STUDY}

U. Kiltz ${ }^{1}$, J. Brandt-Juergens ${ }^{2}$, P. Kästner ${ }^{3}$, E. Riechers ${ }^{4}$, D. Peterlik ${ }^{5}$, H. P. Tony ${ }^{6}$. ${ }^{1}$ Rheumazentrum Ruhrgebiet/Ruhr-Universität Bochum, Rheumazentrum Ruhrgebiet, Herne, Germany; ${ }^{2}$ Rheumatologische Schwerpunktpraxis, Rheumatologische Schwerpunktpraxis, Berlin, Germany; ${ }^{3}$ Ambulantes Rheumazentrum, Ambulantes Rheumazentrum, Erfurt, Germany; ${ }^{4}$ Medizinische Hochschule Hannover, Klinik für Immunologie und Rheumatologie, Hannover, Germany; ${ }^{5}$ Novartis Pharma GmbH, Immunology, Hepatology \& Dermatology, Nürnberg, Germany; ${ }^{6}$ Medizinische Klinik II, Universitätsklinik, Rheumatology/ Immunology, Würzburg, Germany

Background: Gender disparities in PsA can affect natural course of disease, clinical presentation and response to medication ${ }^{1}$. The German non-interventional study AQUILA provides real-world data on the influence of gender of patients with psoriatic arthritis ( $\mathrm{PSA}$ ) on therapeutic effectiveness and retention rate under treatment with secukinumab, a fully human monoclonal antibody that selectively inhibits interleukin-17A

Objectives: The aim of this interim analysis is to describe selected baseline (BL) demographics, to evaluate secukinumab treatment outcomes on disease activity, depressive mood and retention rate depending on the gender of PSA patients. Methods: AQUILA is an ongoing, multi-center study including more than 3000 patients with active PsA or ankylosing spondylitis. Patients were observed from BL up to week (w) 52. Real-world data was assessed prospectively and analyzed as observed. Data was collected on impact of disease (Psoriatic Arthritis Impact of Disease - 12 items, PsAID-12 score), skin disease activity (Psoriasis Area and Severity Index, PASI), joint counts and severity of depressive mood (Beck's Depression Inventory version II, BDI-II), in addition to patient's global assessment (PGA). Moreover, retention rates (time from study inclusion until premature secukinumab treatment discontinuation) were assessed through Kaplan-Meie plots. This interim analysis focuses on the subgroups of male and female PsA patients.

Results: At BL, 1278 PsA patients were included: $41.5 \%(n=531)$ male and $58.5 \%(n=747)$ female. Demographic data (Table 1) of male and female PsA patients differed most obviously regarding proportion of overweight patients, smokers, pretreatment with nonsteroidal anti-inflammatory drugs (NSAIDs) and biologicals/biosimilars (b-bsDMARDs).

Mean PsAID-12 values over time were higher in women; nevertheless, PsAID-12 improved comparably for both genders from $\mathrm{BL}$ to week $52(\hat{\delta}: 4.8$ at $\mathrm{BL}$ to 2.9 at w52, $9: 5.3$ at $B L$ to 3.5 at w52, Figure $1 \mathrm{~A}$ ). This was similar to the course of improvements for mean PGA across genders $(\delta: 4.9$ at $B L$ to 3.0 at w52, $q: 5.6$ at $B L$ to 3.5 at w52). In terms of PASI scores, both BL mean values and improvements over time were similar across genders $(\delta: 6.8$ at $B L$ to 1.9 at w52, $9: 7.0$ at $\mathrm{BL}$ to 1.0 at w52). Mean joint counts (tender/swollen) also improved similarly ( $1: 6.8 / 3.7$ at $B L$ to $3.1 / 0.9$ at w52, $9: 7.3 / 3.7$ at $B L$ to $2.8 / 0.9$ at w52). Over time, male patients showed overall reduced BDI-II values; nevertheless, BDI-II reductions were comparable across the genders $(0: 10.2$ at $B L$ to 8.1 at w52, $9: 13.0$ at $\mathrm{BL}$ to 10.6 at w52). Secukinumab treatment retention rate for men was (not significantly) higher than for women (Figure 1B).

Conclusion: In a real-world setting, secukinumab improved disease activity and depressive mood of PsA patients in both men and women. Women showed overall higher burden of disease. Altogether, this interim analysis shows that secukinumab is an effective treatment up to 52 weeks with high treatment retention rates in real-world setting, irrespective of gender.

\section{REFERENCES:}

[1] Eder, L., Chandran, V. \& Gladman, D.D. Int J Clin Rheumtol 7, 641-649 (2012)

Table 1. Overview of baseline characteristics in PsA patients depending on gender

\begin{tabular}{lcc}
\hline Demographics* $^{*}$ & Male (N=531) & Female (N=747) \\
\hline Age, years & $51.9(11.6)$ & $53.1(11.2)$ \\
$\mathrm{BMI}, \mathrm{kg} / \mathrm{m}^{2}$ & $29.1(4.9)$ & $29.0(6.4)$ \\
$\mathrm{BMI}>25 \mathrm{to} \leq 30 \mathrm{~kg} / \mathrm{m}^{2}, \mathrm{n}(\%)$ & $219(42.8)$ & $211(29.5)$ \\
$\mathrm{BMI}>30 \mathrm{~kg} / \mathrm{m}^{2}, \mathrm{n}(\%)$ & $188(36.7)$ & $285(39.8)$ \\
$\mathrm{Smoker}, \mathrm{n}(\%)$ & $103(19.4)$ & $196(26.2)$ \\
PsAID-12 & $4.8(2.2)$ & $5.3(2.2)$ \\
$\mathrm{PGA}$ & $4.9(2.6)$ & $5.6(2.4)$ \\
PASI & $6.8(9.8)$ & $7.0(11.1)$ \\
Tender joint counts & $6.8(7.9)$ & $7.3(7.4)$ \\
Swollen joint counts & $3.7(5.3)$ & $3.7(5.0)$ \\
BDI-II & $10.2(8.8)$ & $13.0(9.4)$ \\
Medication prior to secukinumab & & \\
initiation, $\mathrm{n}(\%):$ & $290(54.6)$ & $467(62.5)$ \\
NSAID & $460(86.6)$ & $678(90.8)$ \\
csDMARD & $299(56.3)$ & $477(63.9)$ \\
b-bsDMARD &
\end{tabular}

${ }^{*}$ variables given as mean (SD)

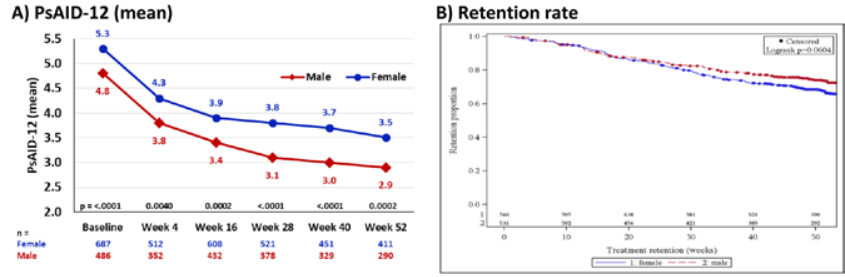

Figure 1. Impact of disease and treatment retention in PsA patients stratified by gender A) PsAID-12 (mean) B) Retention rate Note: P-values are of exploratory nature 